\title{
THE KING EDWARD VIII HOSPITAL PHYSIOTHERAPY SCHOOL, DURBAN
}

\author{
G. H. JONES, M.C.S.P., Dip. T.P. \\ C. A. LIGGINS, M.C.S.P., Dip. T.P.
}

The training of non-white physiotherapy students began in 1964, with the opening of the King Edward VIII Hospital Durban School of Physiotherapy. The first students qualified in 1967 and since then and 1970, 35 students have obtained diplomas and most are now practising in the Republic. There are currently 38 students in training.

Most of these students are from the four provinces, sponsorship being provided by the Natal, Orange Free State and Transvaal Administrations. Other sponsorship has been provided by the National Council for the Care of Cripples and an Anglican Church body in the Transkei. In addition there are two students from outside the Republic, one from Lesotho and the other from Swaziland.

Basically the training of non-white physiotherapists varies little from that of any other group. There are the same groups of good, bad and indifferent students, the same proportion of "won't-works" and "can't-works", of smart guys and dim-wits, that nay be found in any group of students. Superimposed are the special factors which make the job of training non-whites more challenging, and less simple.

For instance, your student may disappear for two or three days. You take no action, because several things may have happened which will be resolved if left alone.

Then, thinking to teach hydrotherapy, in the absence of a hospital pool you arrange to visit an open-air public pool, permission is most readily granted by Authority, but only for one race group, so the lessons have to be repeated for each group.

Examinations are trying for anyone entering students, but the trial is increased when five examining bodies become involved, each with its own rules and regulations, and forms to be filled in - in duplicate or triplicate!
The work, however, is the most rewarding of all. Teaching is, or should be, always a rewarding part of the profession to pass on knowledge, to mediate knowledge of others, to generations of students who will help to form the professional body of the future, is a worthwhile vocation at any time. It is made incomparably more so in South Africa, where the shortage of physiotherapists is so acute, and where the need for physiotherapy is so widespread, and where, in pursuance of Government policy, each race group should be served by its own nembers.

It is perhaps unnecessary to point out that such a goal is a long way from being reached and will take a long time to attain, when only 12 students per annum can be accepted and when three or four of these can be expected to drop out for one reason or another. Expansion of this training is therefore to be hoped for. If all applicants, who are academically qualified, could be given the opportunity to train, many more would start. Some would still drop out, but the total trained would be higher and the final result would depend upon truc merit, not upon blind choice to be made between two or more applicants of the same matriculation standard.

At the tinse of writing, of 35 students that have qualified from the King Edward VIII Hospital Physiotherapy School, only four are not practising, due to domestic reasons. Three are in private practice, eight work in mission hospitals, three in government hospitals, 12 in provincial hospitals, three in mine hospitals and two are working in London. It is very gratifying to receive good reports of their work from all parts of the Republic and overseas. The Durban School enjoys reciprocity with the physiotherapy professional bodies in Australia, Canada, New Zealand and the United Kingdom.

The foundations are laid and we hope that the school will now both progress and expand. 